\title{
The Duplication of Love's Reasons
}

Tony Milligan

In what follows I will presuppose that there can be reasons for love. My grounds for doing so are both simple and familiar: when asked questions such as 'why do you love her rather than someone else?' we are not ordinarily lost for words (Kolodny 2003: 137). This sense of the appropriateness of an answer could, of course, be misleading. A spurious practice of justifying love might mimic other and more defensible practices. But there is at least one good reason for thinking otherwise: it is difficult to abandon the idea that love is an emotion, or that it is emotion-like, and that emotions in general are responsive to reasons by virtue of their cognitive dimension, or their conative dimension, or (better still) both (Helm 2010: 33). The contrasting 'no-reasons' view, typified by Harry Frankfurt's work on love, draws upon a moral psychology which requires us to deny this. It posits reasons for belief and for action but not for other, more desire-like or volitional states which are understood to be states of a radically different sort, they give us reasons to act but are not themselves justifiable (Frankfurt 2004). This rival moral psychology is one that I find it hard to buy-into.

The particular question that I want to address is whether or not love's reasons attach to individuals in a special way. Suppose, for example, someone were to be duplicated, with all of their physiological traits copied onto another, indistinguishable (or even more or less indistinguishable) being. Might various reasons for loving the original also be duplicated in the process? Or is there something about individuals, love or reasons that 
places reasons for love beyond such duplication or, more strictly, beyond comprehensive duplication? I am tempted to say that there is.

Because I will be addressing the apparent inseparability of reasons from persons what follows may have various implications for an account of personal identity. But my interest will be a love interest rather than an identity interest. I will advance the view that while physiological properties can, at least in principle, be duplicated, the same is not true for any full set of reasons for love. If this is correct then it does seem that love's reasons attach to particular individuals in a special way. This may be regarded as one aspect of the uniqueness of persons, in particular those we love, and anything that may shed light upon the latter is worth saying.

My argument strategy will be both simple and, in terms of the conclusion, modest. That is to say it will stop short of any demonstration that a comprehensive duplication of reasons is inconceivable or impossible. Instead, I will attempt to show that familiar scenarios which, at first blush, seem to involve a comprehensive duplication of love's reasons, do not in fact do so. The first scenario (from Derek Parfit) is under-described and leaves open the possibility that everything could be as stated without any such duplication taking place. The second scenario (from Stanislaw Lem) turns out to involve physiological duplication but a clear absence of any associated and comprehensive duplication of reasons. While other scenarios may be offered, these do look (initially) like promising cases. Their failure contributes to the case against duplication albeit it does so without conclusively demonstrating its impossibility. What will also count against duplication (by which I again, mean comprehensive duplication) is the fact that it is surprisingly difficult to imagine what any clear instance of it would actually look like. Considerations that block off a 
comprehensive duplication of reasons in the Lem case turn out to be sufficiently general that they may well apply elsewhere.

\section{Parfit's Scenario}

Derek Parfit invites us to imagine a Scanning Replicator that is used by all the members of a community who are over 30 years of age (Parfit 1992: 290). Each year they have their bodies and brains destroyed by a scanner as part of a process that produces a healthier and more vigorous replacement copy with the full preservation of what Parfit calls 'quasi-memories' (Parfit 1992: 295). Each year a different result is obtained. A body that is based upon an age-30 template is combined with a neural structure that is based upon (but presumably not identical with) that of the individual community member at the time they entered the duplicator. Even with this level of detail, Parfit's scenario is still a little thin. For full preservation of functionality, alterations will have to be made. Steps to prevent neural degeneration, glial depletion and all manner of neurophysiological problems will have to be taken. Otherwise, catastrophic individual and social problems will emerge over time i.e. the community members will ultimately end up senile but just so long as someone remembers how to work the machinery they will all have impressive physiques.

As well as steps to prevent a steady neural degeneration, at least some neural readjustments to undo compensation for the year long body-aging process may also have to be undone. Let us, nonetheless, stick with Parfit but allow that the unwelcome annual ageing-effects can be removed while psychological continuity of a sort can be maintained. Over time, the community members may grow wiser, or at least they grow more 
psychologically laden, but they never grow physiologically or neurophysiologically older by more than 365 days, give or take a day or two to cope with minor inconveniences. This scenario allows Parfit to make a significant claim about love and the love in question is the kind of intimate and deeply personal love that we may have for someone with whom we wish to share our life and presumably our bed.

Due to acceptance of the practice of duplication, and due to the psychological continuity that it affords, the disruption of community life that results from duplication may be assumed to be minimized although the process itself might remain perplexing to an outsider. In spite of such perplexity, Parfit believes that, even for an outsider, there is a correct answer to questions about whether or not a duplicate would and ought to be loved. 'Suppose that I am a person who has moved into this different community. I fall in love with Mary Smith. How should I react after she has first used the Replicator? I claim both that I would and that I ought to love her Replica. This is not the "ought" of morality.' (Parfit 1992: 295). This commits Parfit to the view that there can be reasons for love. And by tagging on the qualification about the kind of 'ought' that is in question, he indicates that what concerns him is the 'ought' of having, recognizing, responding to and acting upon justifying reasons.

He is, however, non-committal about what these reasons can be. For Parfit, reasons for love are obviously tied to physiology and neurophysiology but beyond that his account is a place-holder account, it indicates that something occupies the role of reasons for love but we may not be sure about exactly what. Unsatisfactory though this may be, it allows Parfit to assume that whatever reasons someone has to love a person will be duplicated as a result of the duplication of that person's physiological and neurophysiological traits. This is 
what is captured in his claim that there can be no good reason for loving the Mary Smith who steps into the Replicator at $t_{1}$ but failing to love the Mary Smith who steps out at $t_{2}$. Or at least this will hold subject to some qualifications. Replacement must be serial, it must result in the existence of only one token of the Mary Smith type at any given time, otherwise our limited capacity for love may be placed under strain. Moreover, the gap between $t_{1}$ and $t_{2}$ will have to be sufficiently small to allow for a sense of continuity. A complication would arise should the person who loves Mary Smith becomes accustomed to her loss.

Other qualifications could no doubt be specified but the crux of the matter remains the same: for Parfit, not only could there be a duplication of particular bodies, but such a duplication would involve a comprehensive duplication of reasons for love. This is the view that I wish to undermine. I must confess that it is rather tempting to dismiss it by fell-swoop, through an appeal to general considerations about the nature of love, and specifically by appeal to the way in which love seems to involve an attitude towards the past by contrast with an attitude towards an immediately present other (Cockburn 1990: 158). Parfit seems to regards love's familiar concern for the past as sufficiently covered by the continuation of 'quasi-memories' and in doing so it is arguable that he does not give due credit to the objection that 'quasi-memories' are not memories at all, that they are simulacra and that love requires an actual shared history. This counter-view of love, a relationship approach, can be set out in various ways. It need not commit us to one account of why relationships matter rather than another, it does not require us to say, with Kolodny that love involves valuing the relationship itself or, with Abramson and Leite, that love is a response to another, and to their character traits, in the context of a relationship (Kolodny 2003; 
Abramson and Leite 2011). But it does require that love is possible only where there is a shared history and hence a relationship of some sort.

I will not at this point hide my sympathies. My position is motivated in part by my commitment to such a relationship account. But Parfit's scenario poses a genuine problem for the latter, a problem that concerns the psychological compellingness of love. There may at least seem to be a mismatch between a relationship theory of love (of whatever sort) and the psychological compellingness of love for an immediately present duplicate. Put otherwise, Parfit successfully connects how we ought to respond to a duplicate with how we would actually respond to them. After all, how could any of us fail to see them in a special light? The psychological pressures upon us to accept the love of such a being, and under some circumstance to love them in return, would be immense. And in the face of such compelling pressures, it may seem strange to deny that physiological duplication generates reasons for love.

However, this consideration on its own will not do the work that Parfit wants it to do. The scenario that he describes does not show that there has been a duplication of love's reasons rather than the generation of reasons of some sort. We may allow that the pressures to love or to try to love a duplicate could well be irresistible and that we might also have genuine justifying reasons for loving them. We might not be lost for words when asked 'Why do you love this person?' But while our reasons for loving a duplicate might be genuine reasons they need not be the same reasons as those for loving the original. That is to say, Parfit could be right both about what we would do and about what we ought to do, but not because of a comprehensive duplication of love's reasons. 
What will then be owed in order to make sense of this, as the best description of what physiological duplication involves, is some account of how we can make sense of the love in question as a new love rather than the continuation of an existing love. But for this, we will need more than an impoverished narrative (by which I mean a certain, familiar and truncated kind of thought experiment) and more than a place-holder approach towards love's reasons. We will need an enriched narrative, one that can help us to understand the kinds of consideration that may count as reasons for love.

\section{Lem's Scenario}

For the latter, I will turn to Stanislaw Lem's Solaris, with its fuller back-story about life and loss. This is a scenario which is frequently alluded to and cited in discussions of love and replaceability (Grau 2010: 17; Milligan 2011: 104-6). The version under consideration here will be Lem's original text rather than the film by Tarkovsky or by Steven Soderbergh where the driving force of the scenario is egocentricity and a delusional sense of continuity. (The latter point has been argued convincingly by Christopher Grau (Grau 2013)). In the book, the central character, Kelvin, arrives at an observation station situated above a strange ocean-covered planet. The ocean is unlike any that we know. It is in continuous movement and can mimic whatever it encounters. The sea of Solaris has the unlikely ability to form duplicates of those you have loved and lost. It can 'return' to you whoever you happen to desire most deeply: a child, a lover, a spouse. On an alternative reading, it can body-forth someone from your past who is connected to a deep sense of guilt. 
Kelvin, who is trapped in a protracted decade-long bereavement for his wife, is visited by one of these duplicates, a woman who seems, to all intents and purposes, to be her. As in Parfit's scenario (where brain structure would need to be altered to remain in good order) there are some low-level physiological differences between the original and the duplicate but there is apparent psychological continuity of a substantial sort. There are also some more obvious novelties such as a capacity for recovery from extreme trauma and an infantile tenderness about the feet, 'The skin was soft, like that of a newborn child', a symbol, no doubt, of both vulnerability and difference of identity (Lem 2003: 59).

With one notable exception, all of the differences are such that they need not operate as a reason why the duplicates should not be loved. The notable exception is a behavioural difference: the duplicates cling. They find it impossible to tolerate absence or distance and this helps the reader to sustain a sense that the duplicates really are other than the original. This mixture of psychological continuity (for the most part), together with a small number of novel features, helps the author to present a plausible narrative that involves psychologically-compelling reactions of the sort that Parfit brings into play. The duplicates are difficult to dismiss as fakes or forgeries. Kelvin is attracted to the duplicate of his wife. She seems to hold out the possibility of a loss undone and a longing finally satisfied. But there is also something threatening about these beings. The scenario taps into a sense of unease that is a familiar feature of literature about changelings and doppelgangers.

The first duplicate that Kelvin meets is tricked into a rocket. He shoots her off into space. The second he comes to love, or at least he claims to do so. And one plausible reason for such love is her connection to the original. After all, Kelvin does not become erotically entangled with anyone else on the base but only with the duplicate of the woman that he 
has already loved and lost. This is rather more than a coincidence. But if the duplicate is loved by Kelvin without any belief that she simply is his wife, it may be difficult to reduce the reasons for his love to the fact that she has much the same hair, eyes, teeth and smile as his wife and that these things always happen to trigger his capacity to love. That would, after all, make love fetishistic (Velleman 1999: 370). In Kelvin's case the narrative gives us little choice but to regard his love as both genuine and bound up with the past, more specifically with the past that he shared with his wife, Rheya (I shall intermittently refer to her as Rheya $_{1}$ and the duplicate as Rheya $a_{2}$, ignoring in the process the unfortunate Rheya who arrives too soon and is shot out into space). Kelvin's response to the duplicate is, more specifically, bound up with his sense of guilt about the past, about the role that he played in his wife's suicide. The Lem scenario presupposes that reasons for love, including those for love of a duplicate, must emerge out of some prior relationship but not necessarily a relationship in which both parties were participants. And this too gives it an added layer of plausibility. If the duplicate genuinely is loved by Kelvin, our most plausible account of why this is the case will appeal to her having various properties and to the fact that they help Kelvin to see her as someone with a special connection to his wife and to his past, a connection that nobody else on the base happens to have.

But although this difficult-to-spell-out connection to his wife contributes to what appears to be love on the part of Kelvin, it does not do so because the connection is seen as one of identity or of a Parfit-like continuity that is (pretty much) as good as continuity by ordinary means. In the book, if not in the more recent film version, Kelvin claims to love the duplicate for who she is now, 'I am not the woman you once loved,' says the duplicate, 'Yes. But that was a long time ago. That past does not exist, but you do, here and now.' (Lem 
2003: 149). There is, admittedly, something disingenuous about Kelvin's claim that he disregards the past. After all if he was capable of such an attitude then he would not be in his current predicament. But his denial of the past need not be read as a sheer flight from the reality of his situation. It is, at least arguably, a symptom of the difficulty that he faces when trying to think of the two women separately. Even so, the claim that he loves the duplicate (a claim which I will take to be utterly sincere when made by Kelvin) does not presuppose that he lapses into the view that Rheya 2 , who is connected to Solaris, and Rheya ${ }_{1}$, who was connected to the Earth, are really one and the same woman. Tempting though it may be to unify the two, as soon as he strokes the feet of Rheya 2 there is a physicality to his grasp of their separateness, 'I knew then it was not Rheya, and I was almost certain that she herself did not know it' (Lem 2003: 59). This is an innocence of her predicament that does not last.

\section{Differing Reasons for Love}

In order to help clarify the varying reasons that can plausibly be attributed to Kelvin for loving his (now dead) wife and for loving the duplicate $\left(\right.$ Rheya ${ }_{2}$ ) I will review some of the significant differences between the two. Bracketing-off the clinging behaviour of the duplicate, setting aside the low-level differences of biochemistry and the softness of her feet, the most obvious difference between the original and duplicate is that the original was there when the duplicate was not. If the Kelvin- Rheya ${ }_{1}$ relationship was, in a familiar sense, normal then Rheya ${ }_{1}$ will have been the person who cheered Kelvin when he was sad, put his interests before her own on some occasions and at other times put her interests first (and that too may have allowed him to grow and learn). She will, no doubt, have seen him when 
he was weak and vulnerable but done so without turning away. Unlike the duplicate, she will also have loved him through her own agency and thereby have allowed him to recognize that he too could be loved by another in precisely the way that most of us want to be loved. Again, assuming some normal conditions, Kelvin would no doubt have been loved by his parents (if they were around during his childhood) but love of that sort is unearned, it is not a vindication of who we are. Considerations of this type, such as her being there and allowing Kelvin to see himself in a certain favourable light, are not reasons for love in the sense that they would force love upon any rational agent (it is not obvious that there can be any reasons of the later sort). But they are, nonetheless, contributory reasons for love. And an appeal to them may be in line with a relationship account of love. Such reasons for love are bound up with the history that the original Rheya ${ }_{1}$ shared with Kelvin.

The duplicate is also connected to this same history. Love for her does not require abandonment, as opposed to modification, of the relationship view. However, the duplicate is connected to this history in a different and more indirect way. She is heir to historicallyformed thoughts, desires and emotional dispositions by virtue of a past that is not her own. She has not come to have her thoughts and desires, or more generally to love Kelvin, through her own agency. Her love for Kelvin is, in that sense, curiously akin to parental love rather than to the love of the original for Kelvin. The latter was earned, or (less awkwardly and more deeply) it was mysterious, inexplicable and incredible good luck in a way that parental love is not. The love of the duplicate, by contrast, is entirely to be expected given the fact that she is a duplicate. What is unexpected or incredibly good luck, is the sheer existence of Rheya ${ }_{2}$ and not her love. 
Nonetheless, there may be some reasons for Kelvin to love the duplicate that are also reasons for loving the original. They will certainly have various things in common. They will, for example, share various dispositions to induce certain kinds of responses from others. If you like the look of Rheya ${ }_{1}$ without any further knowledge or acquaintance then you will like the look of Rheya ${ }_{2}$ under the same conditions. More importantly, if some manner of real duplication has occurred they will both have the same admirable character traits and the same sense of humour, both of which will have emerged out of the original's past but which have now come to be (figuratively) common property. These considerations, virtuous character traits and sense of humour, can (again figuratively) speak to a person's heart. They might be cited in response to the question 'Why do you love her rather than someone else?' When supplemented by a larger story, the answer might not seem misplaced.

As well as reasons to love that attach exclusively to Rheya ${ }_{1}$ ('she was the one who was there'; 'she loved me through her own agency') and reasons to love both ('she needs me' and 'her sense of humour speaks to my heart', 'she is so gentle') there may be reasons to love that attach only to Rheya ${ }_{2}$ because they are reasons which are bound up with her being a duplicate and not the original.

Here, I am not alluding to the low-level physiological differences. I will assume that Kelvin did not love his wife back on Earth because of the texture of her skin, nor does he love the duplicate at the Solaris station because of the childlike tenderness of her feet. Yet the latter is not unconnected with some special reasons for loving her. Her soft, childlike feet are after all a symbol of her special predicament and vulnerability. And vulnerability is something that may, again, speak to the heart. It is a non-trivial consideration that regularly 
figures in accounts of love which are sympathetic to the 'reasons' position (Velleman 1999:

365; Abramson and Leite 2011: 688). The slightly different kind of vulnerability that is made evident by the duplicate's clinging behaviour may similarly count as a special sort of reason for loving the duplicate. It is, after all, a vulnerability that is bound up with her loving Kelvin. And while her clinging in certain respects parallels the original's need for Kelvin, it is clinging and vulnerability in the context of an extreme situation that the duplicate and only the duplicate shares with Kelvin. Such sharing of an extreme experience can itself be a reason for love. People bond in adversity. Their shared predicament is also one for which she carries no fault. It has been inadvertently brought about by Kelvin and in some sense by the planet Solaris. This leads me to another, and perhaps even more striking feature of the duplicate that was in no way a feature of the original. The duplicate originated in a marriage of Kelvin's own desires and guilt with something other and utterly alien. As such, Kelvin stands in a quasi-parental relation to her. If anything counts as a reason for love, the parental relation does so but it is, again, a relation that he has only to the duplicate and not to the original. In a sense Rheya ${ }_{2}$ is the child of his thoughts, desires and perhaps also his guilt.

\section{Two Problems}

Insofar as the Parfit scenario and the Lem scenario are reliable exemplars, what seems to the case is, firstly, that physical duplication could involve the duplication of some reasons for love, but no more than some. The Parfit scenario leaves open the possibility that an agent's reasons for loving the original and their reasons for loving a duplicate may in fact differ. The Lem scenario can then be used to support the view that they will differ. 
But this is a picture that itself may need qualification. I have, perhaps, conceded too readily that the psychological compellingness of our response to any duplicate of someone we love must itself be a matter of love. When Kelvin initially encountered the duplicate, Rheya $_{2}$, he may have had only reasons to come to love her and not, in the first instance, reasons for love. After all, Kelvin loved his wife back on Earth and this love involved (or rather involves, for the love continues) a form of intimate care. What makes the care intimate, as opposed to being care of the sort that we may associate with benevolence towards strangers, is something beyond sexual togetherness or the sharing of various private bits of information. What makes the care intimate is, at least in part, Kelvin's desires. Some of his desires are bound up with his well-being, they must be satisfied if he is to flourish or, more modestly, to be content. But some of these desires will be conditional desires. More specifically, they will be conditional upon the well-being of whoever he happens to love (just so long as he does indeed love someone). Given that Kelvin loves the original, Rheya ${ }_{1}$, these desires will be impossible to satisfy now that she is dead. But her death will not have made these desires simply go away. The upshot is that without her, Kelvin cannot be content and he is not content. He is a bereaved and haunted man.

An important part of Kelvin's grieving process may be understood as a partial disentanglement that (up to a point, or to some extent) will help to removed the conditionality of his desires upon the original Rheya's well-being and proximity. The appearance of Rheya ${ }_{2}$ may be understood in the light of this. Her appearance will not satisfy any of his impossible desires (the desires that require the well-being of Rheya ${ }_{1}$ ) but it may at least seem to open up the possibility of accelerating the process of partial disentanglement. 
It will do so given that one of the best ways to recover from love and loss is to love someone else and thereby to break out of familiar and egocentric patterns of preoccupation.

In the light of this rudimentary account of the intimate nature of the concern that Kelvin still has for his dead wife, concern that makes his grief and sense of loss intelligible, let us now consider the predicament of Rheya ${ }_{2}$ and Kelvin's claim that he loves her but that he does not love her simply as a copy. This is a claim that might be met with some scepticism. The duplicate herself, when she realises that she is a duplicate, is not convinced. Even so, the genuineness of her feelings do not seem to be in question (at least insofar as we think of her as a genuine duplicate rather than some more fragmentary projection from Kelvin's psyche). Some externalist doubts can probably be raised about her responses ('is her concern really about Kelvin?'; 'are her thoughts really about the same past that was experienced by the original?') but there may turn out to be no good grounds for regarding her emotions as false emotions by appeal to the fact that they lack an appropriate causal background (Milligan 2008: 217-21). If we are unpersuaded by such externalist doubts then we may perhaps accept that her emotions piggy-back upon the suitably-formed emotions of her predecessor. The duplicate will then love Kelvin just so long as the original did so. And this may, up to a point, count as a contributory reason for Kelvin to love her in return, albeit it will count as a defeasible reason for him to do so. It would be odd to say that we must always continue to love others simply because they love us, but the fact that they do love us can be relevant to the emergence and continuity of our own love.

If we accept the rudimentary account of love's intimacy that has been given above (such that it involves a deep entanglement by means of conditional desires) there may be no difficulty in accepting that the duplicate loves Kelvin but it no longer looks obvious that 
Kelvin can love the duplicate. If he thinks that she is the original he will not be loving her, and if (as seems to be the case) he accepts her standing as a new and different being then he still cannot love her because entanglement by means of conditional desires takes time to develop (at least in the case of any normal agent such as you, me and Kelvin). The duplicate can love suddenly but only because she is not a normal agent with a normal history. But Kelvin's own desires cannot be conditional upon the duplicate's well-being or her proximity because such conditionality takes time to emerge (also to disappear). There could, for example, be no simple switch of allegiance by Kelvin from his wife to the duplicate. In some sense, he must still love his wife, and this consideration may be in play when Kelvin attempts to differentiate his new love from his old love. He seems plausibly to read his predicament as one of mixed or dual allegiance. But it is still rather difficult to see exactly how he could love the duplicate at all on such a short acquaintance. Given this, it is at least tempting to say that Kelvin is wrong to imagine that he loves the duplicate for who she is not because he is delusional but because he does not love her at all, at least not at first. The shared history between Kelvin and his wife arguably enables the duplicate to love Kelvin without initially enabling Kelvin to reciprocate.

\section{Conclusion}

In line with the above, if we accept that normal agents (people like us) cannot instantaneously love duplicates it will lend further plausibility to the claim that any love for the latter that might emerge over the course of time will be in important respects discontinuous with and unlike our love for the original person. It is therefore, again, unlikely 
to be love that is responsive to (or justifiable by appeal to) exactly the same set of considerations.

Of course, it always remains possible that someone might come up with a clever duplication scenario in which matters look significantly different. But such a scenario is difficult to envisage. It would have to involve more than a Parfit-style impoverished narrative, otherwise we would not be able to identify the reasons for love in sufficient detail to see that they have in fact been duplicated, and comprehensively so. It would also have to differ significantly from Lem's scenario by involving an instance of unrequited love. If it involved requited love (like the love of Rheya ${ }_{2}$ for Kelvin) there would always be an obvious way to contrast the reasons for loving the original (who reciprocates loves through their agency) and the reasons for loving the duplicate (who reciprocates but only because they have no other option). And what makes appeal to an alternative scenario, featuring unrequited love, slightly awkward is that such scenarios do not show our reasons for love to their best advantage. Yet even in cases of unrequited love there will still be good grounds, of a general sort, for questioning the very idea of an instantaneous (if unrequited) love. For non-duplicates like us, the psychological compellingness of feeling something for a duplicate does not seem to stretch so far.

If the above is correct then there are grounds for saying something like the following: unlike physiological features (whose duplication can readily be envisaged) our reasons for loving others cannot be comprehensively duplicated. In other words, the special cluster of reasons that we may have for loving someone must always attach in some strong way to that particular individual and only to that individual. And this may be regarded as an aspect of their irreplaceability. 
Acknowledgements: this paper was originally delivered at the Reasons of Love Conference held at the University of Leuven in the summer of 2011. Thanks go to members of the audience and to the anonymous reviewers of Philosophical Explorations for a number of useful and improving comments. Thanks also go to Chris Grau and to colleagues in the European Philosophy of Love Group for a recent insightful discussion of Grau (2013) which has, no doubt, fed its way into the final revision of the text.

\section{Bibliography}

Abramson, K., and A.Leite. 2011. Love as a Reactive Emotion. Philosophical Quarterly, 61, no. 245: 673-99.

Cockburn, D. 1990. Other Human Beings, New York: St Martin's Press.

Frankfurt, H. 2004. Reasons of Love, Princeton: Princeton University Press.

Grau, C. 2010. Love and History. Southern Journal of Philosophy, 48, no.3: 246-71.

Grau, C. 2013. Love, Loss and Identity in Solaris. Forthcoming in Christopher Grau \& Susan Wolf (eds.) Understanding Love through Philosophy, Film and Fiction, Oxford University Press.

Helm, B. 2010. Love, Friendship and the Self, Oxford: Oxford University Press.

Kolodny, N. 2003. Love as Valuing a Relationship. The Philosophical Review, 112, no. 2: 13589.

Lem, S. 2003. Solaris, London: Faber and Faber.

Milligan, T. 2008. False Emotions. Philosophy, 83, no. 2: 212-30.

Milligan, T. 2011. Love, Durham: Acumen.

Parfit, D. 1992. Reasons and Persons, Oxford: Oxford University Press.

Velleman, D. 1999. Love as a Moral Emotion. Ethics, 109, no. 2: 338-74. 